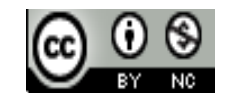

Journal of Education, Teaching, and Learning is licensed under

A Creative Commons Attribution-NonCommercial 4.0 International License.

\title{
Diverse Roles ANd ACADEMic PERFormance OF Tertiary STUdents in MASVingo, ZiMbABWE
}

\author{
Lokadhia Manwa \\ Great Zimbabwe University, Masvingo, Zimbabwe \\ E-mail:manwal@gzu.ac.zw
}

\begin{abstract}
Tertiary student roles are a critical aspect of student life during their academic career as they significantly contribute to the success of the whole learning process and the accomplishment of the entire course. This study contributes to debates on the influence of student multiple roles on academic engagement given the limited research on this phenomenon in Africa and Zimbabwe in particular. By investigating the factors influencing the nature of students' roles, the findings may influence researchers to investigate other aspects of students' life situations. The study sought to explore from the students' perspectives, how they juggle their roles and from lecturers how these students perform. A qualitative approach that employed convenient sampling used twenty-one students and six lecturers from the three tertiary institutions in the city. Open-ended questionnaires and in-depth face-to-face interviews were used to generate data from the participants. Thematic analysis was used to process data, whereby common ideas and patterns that came up repeatedly were coded leading to key issues. Factors such as family background, family life cycle stage and economic status were found to be influencing the nature of students' roles. Students indicated that they occupy many social roles which they could not ignore. They also reported negative effects of these roles on academic engagement. Lecturers also indicated that most students were not performing to their best. The study, therefore, recommends serious consideration of the various interplay underpinning factors that may impact negatively on student role behaviour. The incorporation of time-management and ingenuity into the university curriculum may benefit all students.
\end{abstract}

Keywords: Student Role; Multiple Roles; Academic Engagement; Academic Performance; Student Life; Social Roles

\section{INTRODUCTION}

Most tertiary students are adult learners, who, besides being students, have to attend to other demands and responsibilities in their lives such as being parents, employees, and many others (Meiners, 2017; Reed, 2016; Rowlands 2010; Mamhute, 2011). This means that, even when motivation is there, formidable obstacles remain. Tertiary students in Zimbabwe, due to the economic turndown in the country, may face incalculable challenges when trying to make ends meet instead of concentrating on their studies. This current study captures and conveys the factual experiences of students regarding multiple roles. Thus, there is a need to study the influence of multiple roles on academic engagement and consequently academic achievement. The research objectives were to establish the factors that were influencing the nature of students' roles and how these students' multiple roles influenced their academic performance. This present study is therefore intended to benefit tertiary college administrators in planning students' activities especially the students' affairs.
Tertiary students will also benefit from managing their diverse roles.

Reed \& Kennett, (2017) assert that social and economic changes have shifted the old system of manhood and womanhood and that males and females are faced with incompatible and different roles behaviours. Students are no exception to this situation; society expects them to continue assuming their original duties while they are studying (McKie, 2010; Haralambos \& Holborn, 2008) Thus, institutional impediments such as busy and inflexible schedules may lead to physical and psychological exhaustion due to multiple role load. Students play multiple roles, and each role comes with responsibilities, expectations and rights. Often, these roles become too much for one person, and when roles begin to differ, serious social and psychological problems can result (Koocher \& Keith-Spiegel, 2017). Therefore, ill health and a common sense of caginess are symptoms that follow role load. Giancola (Veney, O'Green \& Kowalik, 2012) stated that life commitments are in perpetual conflict with one another; they compete for the individuals' limited time, energy and resources. Accordingly, most tertiary students, as individuals, have to balance part- 
time jobs, family commitments, and extra-curricula activities alongside their academic commitments (Hom, 2010), making them more vulnerable to role overload. Denning et al. (2018) stated that role overload can be a source of stress and absenteeism among students. In their study, Buda and Lenaghan (2005) studied student-work relationships and found that the two produced stress as they demanded time from students; this negatively affected students' well-being.

Most tertiary students worldwide belong to the early adulthood age group [18-35 years] (Willems, 2010). Veney, O'Green \& Kowalik (2012) affirmed that a shift in the profile of higher education students has taken place with many adults now attending tertiary education. The above situation is true of Zimbabwe as seen in the increased number of mature people attending tertiary education. These students are therefore candidates of the high risk of role overload. The current researcher noted that every person is striving to learn to live a decent life; as the economic situation in Zimbabwe requires one to have a stable job (United Nations Zimbabwe, 2010). Zimbabwean students like all other students worldwide, aim to realize their life aspirations such as career development, starting a family and social relationships leading to the vast variety of activities and livelihoods making it impossible for one person to remain tied to a single social role (Herlihy \& Corey, 2015; Mamhute, 2011). As a result, at this stage of the life cycle, undergraduate students may face difficulty concerning their social roles, personal ideals and ambitions.

Role overload is an expression that can be linked to so many life situations that people are confronted with due to changing values, lifestyles, career patterns and family role expectations (Wilkinson \& Marmot, 2006). In the case of this study, it was recognized that being a student is value shifting and certainly leads to a change in lifestyle. Actual role behaviour differs from expected behaviour for numerous reasons. Some may not see the role the same way others see it, and personality and characteristics affect how one thinks and feels about the role (Van Rhijn \& Lero, 2014; Ritzer, 2008). These life circumstances have the potential to amplify the level of pressure which students experience since peoples' lifestyles and the environment in which they live sturdily influence their health. Role overload can also be expressed as a personal experience that can be explained as tension, anxiety and/or frustration that a student may experience due to role demands.

Research studies have revealed that anxiety while studying is the main predictor of academic performance. It impairs cognitive functions and interrupts reasoning in students (Barrows, Dunu, \& Lloyd, 2013; Vitasari, et al., 2010). As a result, anxiety manifests through psychological or physical symptoms. Herlihy \& Corey (2015) stated that soaring levels of anxiety lead to a reduced memory span, loss of attentiveness, lack of confidence and poor reasoning. In the context of this study, the researcher argues that anxiety leads to difficulty in concentration as it reduces working memory. Students who have elevated levels of stress may become blank in examinations; feel dependent when doing assignments; and lack confidence in presentations.

Studying itself can be stressful, but several aspects of student life can provoke anxiety. These include working while studying, financial burdens, getting along with family expectations and excessive study load (Afolayen et al., 2013; Barrows, Dunn, \& Lloyd, 2013). Vitasari et al. (2010) posit that study anxiety has two dimensions, namely physiological arousal and cognitive anxiety. Fig. 1 shows how to study anxieties affect academic performance.

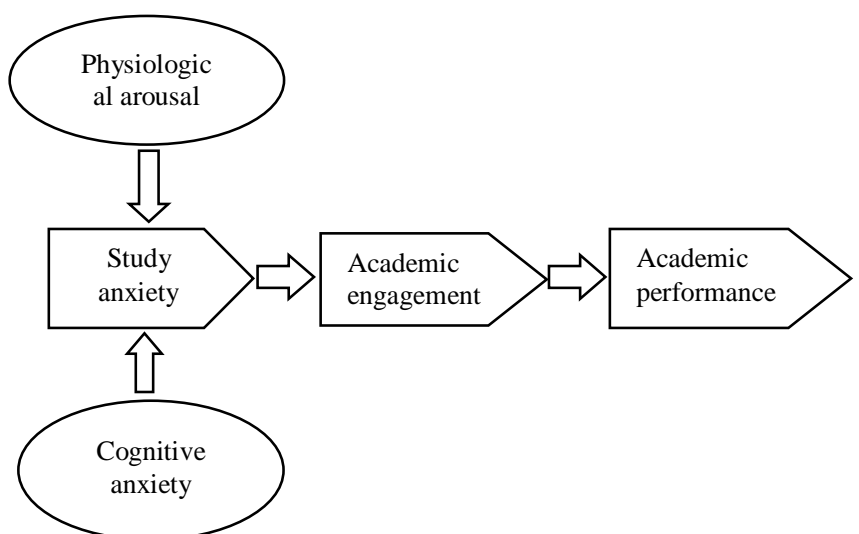

Fig. 1 How to study anxieties affect academic performance (Adapted from Vitasari et al., 2010)

When anxiety is in its severest form, students' minds go blank, they experience the shakes and their hands go numb, sweaty and they suffer some sudden disabilities associated with anxiety during the examination. This will inexorably bring poor results. Research has explained that successful academic performance depends on the effective study and motivational strategies (Safree, Yasin, \& Dzulkifli, 2011). Excessive worrying is one of the forms of anxiety which research identifies as very common among tertiary students (Vitasari et al., 2010; Wakefield, 2013). Greater anxiety is associated with excessive worrying which results in students focusing on worries instead of their student role workload. These situations can be described as lamentation in most students when they are worried about difficult situations related to their study (Vitasari et al., 2010). In most cases, when students are faced with assignment deadlines and examinations, they lament their situation and describe it as unbearable. The weak ones fall sick, become trapped in drug abuse and maybe even drop out. Thus, worrying makes a person's life difficult resulting in a variety of emotional and behavioural disorders (Bhadouria, 2013). In the context of this study, excessive worrying maybe considered one of the major predictions of academic performance since it is impossible to avoid worrying if one fails to meet role demands. Therefore, there is a need for this study because there is limited information on perceived role overload among African tertiary students in general and Zimbabwe in particular.

The study was guided by the following research questions: a) What are the factors influencing the nature of students' roles? 
b) How do the students' multiple roles influence their academic performance?

\section{Methodology}

The study adopted a qualitative approach and a descriptive case study design as it offers the opportunity to gather rich descriptions of the undergraduate students' experiences regarding multiple roles. Through involvement, the researcher managed to obtain in-depth descriptions and understanding of social actions relating to participants' specific situation. This approach was adopted because it is person-centred, holistic and humanistic in perspective and focuses on specific concepts (Denscombe, 2007). This simply means that human experience is what individuals experience directly through the senses, rather than being imagined in the mind as some abstract notions (Denscombe, 2007). Following this point, the qualitative approach concentrates on the kind of human experiences that are pure, indispensable and raw in the sense that they have not been subjected to analysis and theorising procedures (Cohen, Manion, \& Morrison, 2011; de Vos, et al 2011). This means that, in this current study, the experiences of tertiary students are crucial in describing lived experiences and situations.

The current study's population was made up of first-year students at the three tertiary institutions in the city. About two hundred (200) first-year students and twenty (20) lecturers served as the population of this study. A sample of twenty-one (21) students (seven from each institution) and six (6) lecturers [two from each institution] were conveniently selected.

To get credible data from student participants, from each institution two participants (a male and a female) were interviewed while the other five were given open-ended questionnaires. In-depth face-to-face interviews were also used to collect data from the lecturer participants. The instruments solicited data on both broad and specific issues regarding multiple roles and academic achievement. The open-ended questionnaire allowed for anonymity because the participants did not use their real names. It is also an economical way of gathering data in terms of time, effort and cost (Silverman, 2010). Data collected through openended questionnaires were merged with data obtained from in-depth interviews.

Data were thematically analysed. Patterns across data sets were pinpointed, examined and then recorded. This was important as it allowed the description of the phenomenon. Emerging themes were presented and analysed according to the research questions.

Research ethical issues were observed at all stages of this study, paying particular attention to consent and confidentiality. Creswell (2014), stated that the essence of anonymity is critical so that information provided by participants do not reveal their identity. Thus, anonymity was enhanced by the use of pseudonyms for interviews and codes for questionnaires during data collection. All the participants voluntarily participated in this study.

\section{RESULTS AND DISCUSSION}

\section{A. Results}

The majority of the student participants in this study were married, single parents or widowed; very few were single. This demographic information was important because marital status reveals the nature of roles of each person since in the African culture if one does have a family; it means that one has a lot of duties irrespective of their sex. However, mothers are known to be family care-givers. Single people had only two major duties, namely being children and a sibling. These were said to be not too demanding except in child-headed families. Thus, knowing the marital status of students helped the researcher understood the roles they were obliged to play beside their roles as students. All the non-resident students, especially females, indicated that household chores took most of their study time making it difficult for them to research for assignments and class presentations and sometimes household chores led to absenteeism.

\section{1) Factors that influenced the nature of student roles}

Most of the student participants in this study indicated that, besides being students, they performed many other social roles such as being employees, parents, spouses, siblings, friends, offspring, extended family members or inlaws. Factors such as social and cultural capital (family life cycle stage and origin), socio-economic status and economic situation in the country-influenced the nature of student roles. These roles inevitably impacted negatively on their academic engagement and, consequently, their performance, as role multiplicity led to role overload.

Most students, both males and females, showed that their social roles were significantly influenced by the family life cycle stage. The young families with primary school-going children and those with the elderly confirmed demanding family roles which could not be ignored at any cost. One female student indicated that her family was still at a tender age hence all social duties were left to her because the kids were still too young to do anything, instead, they needed much care. Married students, especially females, added gendered duties such as being wives, mothers, carers and house-keeping issues, while unmarried ones mentioned being siblings, as well as looking after parents.

The following responses from student participants illustrate that their family background determined their social roles. One student said:

I have duties of a student, mother, in-law and a wife; I am expected to attend to the individual needs of each member (IR-Bee).

Another student also pointed out that:

As a single mother, I take care of my kids, parents and young siblings because I am the firstborn in the family. $(Q R-E)$.

One other student echoed the same sentiments:

Every day I begin a new day already exhausted. I don't have enough time to rest. Everything is on my shoulders. (IR-Cheu) 
The social statuses of most students required them to perform social roles, with some having undefined duties. These included attending societal issues such as church and community development meetings. Those with mature children indicated that sometimes they felt if they could be torn apart to attend to social issues at the same time with college work. The following responses confirm the findings:

I am a church board member so have to attend to issues that arise at the assembly as soon as possible. These sometimes strain me such that I won't have time for the family or my college work. (IR-Zivu). My twenty-year-old son impregnated a girl. As we speak, I have to go and attend to that issue before the in-laws are too angry for us. (IR-Gonz).

As a student, I am expected to socialise with my siblings, friends, church members and be a peer educator at both college and home. ( $Q R-A)$.

Besides being a student, I'm a husband, in-law, offspring, parent of my biological children and orphans and many other societal duties like presiding over all clan issues. (IR-Bans).

The economic challenge in the country was cited by most students as one major cause of comprehensive duties. The majority pointed out that because of the economic situation, a family cannot rely on a basic salary only. One student participant indicated that everyone in their household was doing something to supplement the family's basic salary. So in her situation, she was not an exception so was selling snacks and sweets to her colleagues. Extended family duties, such as caring for other family members' children (extended family), magnified the duty of sourcing funds. This is another obligation that almost all students mentioned because they all indicated they had to raise money for their tuition fees, typing and photocopying, accommodation fees, and transport fares for those who travel to college as well as funds for general upkeep. All the participants in this study pointed out that they are always caught in between school demands and other social duties. The following excerpts confirm the findings:

Besides being a student, which has so many and challenging assignments, I am an employee, a father who takes care of my immediate and extended family. The major challenge is that our family income is less than one-tenth of the family's basic needs. (QR-O).

I am a single mother. My duties are so many, umm--$m h$, being a woman, the list of all my duties is endless. It includes being a breadwinner and also being a mother and a father at the same time. (IS -Shoo).

2) Students' multiple roles influenced their academic performance

This study established that role contradictory and role contagion negatively influenced the students' learning process. Absenteeism or partial absenteeism was evidence of role contradictory and contagion. Student participants indicated that they did not enjoy their student statuses because they had very tight schedules every day. In most cases, they were physically and mentally stressed. Most of the participating students had some tactics they believed could lessen their burdens, for example, prioritising duties, and budgeting time, sleeping a few hours and reducing communication with their relatives. One student had this to say:

Really it's very challenging and stressful as I spend most of the time trying to prioritise duties. I wonder if I am going to complete my studies before I become barmy (laughing). You know, ummm, family duties will always take a lead so it's like I do the hottest task every time. (IR-Fay).

These sentiments reveal that they are mostly worried about wasting time and that they are struggling to balance issues. This indicates that undergraduate students face challenges in performing their student roles. One student responded as follows:

I am trying to balance issues but certainly, my health is at risk and I always feel I am not performing to my best level. I try to budget my time to the last minute but stress is the order of the day. $(Q R-G)$.

The same challenges were highlighted by another student participant who said that:

Sometimes I ignore lectures especially those of mindnumbing lecturers and sleep very few hours trying to cover up my backlog particularly researching for assignments in the library because I rarely get free time. $(Q R-M)$.

Some students indicated that since they started studying, they have ignored other duties such as sporting and friendship roles, to cut down the number of their duties they now regard as time-wasters. During interviews, a student indicated that:

I no longer attend sporting sessions because of lack of time but I always feel that most of the time I submit hurriedly done assignments. (IS- Joo).

Another student also pointed out that:

I have since ignored friendship roles and even cut communication with most relatives because I can't manage them all. Umm...m, you know, being a student is so challenging and stressful especially when I have to source money in this economic hardship. (IS-Shilo).

When asked to comment on how first-year students perform in assignments and examinations, all lecturer participants revealed that students were overwhelmed with duties to a greater extent because they submitted substandard work. Some assignments showed that they were hurriedly done and most female students asked for an extension of deadlines. One lecturer shook his head as he made the following remarks:

Err.., I am very worried about our students. Most of them submit too untidy assignments indicating that they are hurriedly done. They always lament the shortage of time to do quality work. I always wonder how I can help some of them. (IL-Maje).

The same was echoed by another lecturer who added that: Most female students rarely submit work in time; they always complain of their household chores and 
motherly duties. I always feel for them when they beg for a due date extension but their work is sometimes poor. (IL-Dudu).

Thus, the majority of the lecturer participants concurred with most undergraduate students that they occupy many roles and that most of these roles cannot be avoided. This affected their student role engagement.

When lecturer participants were asked to comment on the assertion that multiple responsibilities affect students' academic performance, the majority concurred with the assertion and argued that occupying many roles leads to divided attention and excessive fatigue. A lecturer identified as Muzee indicated that:

Multiple roles really affect academic engagement because it's natural that an individual will attend to social role demands first before schoolwork or other roles like work duties, thus leading to divided attention. (IL-Muzee).

Another lecturer, Zvitadzo, amusingly said that:

One day I laughed my lungs out when a group of female students were complaining of fatigue and approached me to give presentation assignments to male students only because they have more time to research. You know, I had to do a bit of counselling because males do not write examinations for them. (IL-Zvitadzo).

\section{B. Discussion}

The findings of this study indicate that the majority of tertiary students occupy many roles besides that of being students. Many students in this study were parents, spouses, in-laws, workers, siblings and also played many other social roles. These findings are consistent with Reed \& Kennett (2017) and Wadesango \& Machingambi's (2011) results who found out that most tertiary students are now nontraditional students hence they occupy many roles which are predestined. Multiple roles are an unfavourable factor that leads to unmotivated tertiary students who suffer from increased anxiety of failing to meet the student role expectations (Khwaileh \& Haider, 2011: Whipps-Johnson, 2016). Anxiety negatively affects their ability to learn since they will be busy worrying about failing to meet assignment deadlines, as well as failing to pass examinations. This negatively impacts their academic engagement and their ability to concentrate on their studies.

The findings on multiple roles revealed that the majority of students had a lot of stress from social roles, especially domestic chores for female married students. Among the factors recognized as affecting academic performance, gender and ethnicity were stated as some of the major ones (Anelli \& Peri, 2017; Rafidah et al., 2009). Thus, in the context of this study, most female undergraduate students were overwrought by gender roles. In the African culture, women are the home managers and this means that they play a key role in the family and society. For example, in this current study, female tertiary students were expected to perform their duties as well as do all the domestic chores even though they have to attend to their student roles. This, therefore, exposes them to role stress which leads to physical and mental strain. This means that too much participation in household tasks by female tertiary students reduces their participation during lectures and, subsequently, negatively impacts their academic performance. Similar to these results are Chevalier, Isphording, \& Lisauskaite's (2019) who observed that peer diversity, e. g. female students were overburdened by household chores, causing physical strain and a lack of concentration on their academic work.

The general perception among all the interviewees and questionnaire responses were that students were overwhelmed with social duties and that these naturally affected their academic engagement and, consequently, their performances as students. Thus, in this theme, the study findings point towards role overload. Goode's (1960) characteristic assertion of role strain theory states that multiple social roles are problematic because of overwhelming duties and obligations. According to Goode (1960), role strain leads to role overload, role contagion, role conflict and in some cases role ambiguity. Role strain, in turn, unavoidably leads to worries and apprehension as each role comprises an inherent yet distinct set of entangled responsibilities that present as stressors. These findings confirm that strain is most acute at the beginning when the students are transitioning to tertiary where they must adjust to the new environment and role demands (Koocher \& Keith-Spiegel, 2017: Wakefield, 2013).

It also emerged from this current research that since tertiary students were overwhelmed by duties, the majority did not enjoy performing their roles. These results are consistent with those of the study by Meiners (2017) who argue that tertiary students are rarely exposed to one stressor and these affect all three domains at once, thus, negatively affecting their academic engagement. Though some students indicated that they tried several strategies to solve the problem, for example, sleeping late and waking up early prioritising duties and budgeting time to lessen their burdens; most of these strategies have side effects. The side effects include dozing in lectures, as well as wasting a lot of time planning. In this present study, the impact was also revealed by lecturers who indicated that most students submitted substandard work, doze in lectures and perform poorly in examinations.

Students also admitted that they were stressed by their role expectations especially meeting assignment deadlines and passing examinations as they try to juggle academic and social issues. The majority indicated that they were very worried about their overall performance grades when they complete the programme. Stress and anxiety are bad for people who need to have a free and fresh mind so that shortterm memory can work effectively. This is in line with what Herlihy \& Corey (2015) and de Bruyn (2010) described as unattached academic engagement which leads to substandard work and incompetence in examinations. Thus, the short-term memory, which processes all the information, must not be occupied by other thoughts which disturb attentiveness in class, concentration during the study and recalling of concepts in examinations. 
Another salient finding of this study was burnout. It was not only a factor affecting interpersonal processes but that also affected students negatively during their college life. The students' burnout demotivated them, failing to complete coursework, absenteeism, and even dropping out of college. All these results in poor academic performance. These results are consistent with those of Calvo et al. (2020) and Mamhute (2011) who found out that time constraints put a very grave demand on the physiological, emotional and psychological aspects of the tertiary students and leaves little time for physical and psychological recuperation. This results in the individual being physically and emotionally drained, especially after working and studying without adequate nutrition. The result is that students will lose the focus of any academic work.

\section{CONCLUSIONS}

Based on the research findings, some conclusions were made in line with the research questions. Students' background, family life cycle stage and socioeconomic status influenced the nature of their roles. On the issue of role multiplicity, the study concludes that most students occupied many roles and this led to role overload. Role overload caused divided attention on duty fulfilment. Role overload was seen to impact more negatively on married tertiary students as the social structure determines their duties and resource situations.

The study, therefore, recommends that to improve students' academic performance, the interplay of various underpinning factors should be considered. Family members should not pressure students unnecessarily, for example, if there are issues that need attention in the family, the family must try to solve them without calling them back home.

\section{REFERENCES}

Afolayen, J. A., Bitris, A. O., Adeyanju, B. A. and Agam J. A. (2013). Relationship between anxiety and academic performance of nursing students. Niger Delta University, Bayelsa State, Nigeria.

Anelli, M. and Peri, G. (2017). The Effects of High School Peers' Gender on College Major, College Performance and Income. Economic Journal, 3(1): 55-65.

Barrows, J., Dunn, S. and Lloyd, C. A. (2013). Anxiety, selfefficiency and college exam grades. Universal Journal of Educational Research, 1(3), 204 - 208.

Bhadouria, P. (2013). Role of emotional intelligence for academic achievement studies. Research Journal of Educational Sciences, 2, 8-12.

Buda, R. and Lenaghan, J. A. (2005). Engagement in multiple roles: An investigation of the student-work relationship. The Journal of Behavioural and Applied Management, 6(3), 211-224.

Calvo, S., Luciaelini, L., Morales A., Martínez, J.M.G. \& Utrilla, P. C. (2020). Academic Literacy and Student Diversity: Evaluating a CurriculumIntegrated Inclusive Practice Intervention in the
United Kingdom. Sustainability, 12, 1-14 www.mdpi.com/journal/sustainability.

Chevalier A., Isphording, I. E \& Lisauskaite, E. (2019). Peer Diversity, College Performance and Educational Choices. Discussion Paper Series IZA DP No. 12202

Cohen, L., Manion, L. and Morrison, K. (2011). Research methods in education. $7^{\text {th }}$ Edition. London: Routledge.

Creswell, J. W. (2014). Research design: Qualitative, quantitative and mixed Methods Approaches. Los Angeles, CA: Sage.

de Bruyn, E. H. (2010). Role strain, engagement and academic performance. Netherlands Educational Studies, 31(1), 15-28.

de Vos, A. S., Strydom, H., Fouche, C. B. and Delport, C. S. L. (2011). (Eds.) Research at the grassroots for Social Sciences and Human Science Profession $4^{\text {th }}$ Edition. Pretoria: Van Schaik.

Denning, E. C., Brannan, D., Murphy, L. A., Losco, J. A. and Payne, D. N. (2018). Not All Roles Are the Same: An Examination Between Work-FamilySchool Satisfaction, Social Integration, and Negative Affect Among College Students. Psi Chi, The International Honour Society in Psychology (Special Issue), 23(2), 166-178.

Denscombe, M. (2007). The good research guide for smallscale social research projects. $3^{\text {rd }}$ Edition. London: Open University press.

Dimbisso, T. (2009). Understanding female students' academic performance: An exploration of the situation in South Nations Nationalities and Peoples Regional State Ethiopia. Graduate School of Developmental Studies. The Hogue. The Netherlands.

Goode, W. J. (1960). A theory of role strain. American Sociological Review, 25(4), 483-496. http://www.jstor.org/stable/2092933.

Haralambos, M. and Holborn, M. (2008). Sociology: Themes and perspectives. $\left(7^{\text {th }} \mathrm{Ed}\right)$. London: Unwin and Hyman.

Herlihy, B., and Corey, G. (2015). Boundary Issues in Counselling: Multiple Roles and Responsibilities ( $3^{\text {rd }}$ Ed.). Alexandria, VA: American Counselling Association.

Hom, V. (2010). The triggers of stress in university life. Utopia Research Institute.

Khwaileh, F. M. and Haider, Z. (2011). Gender defences in academic performance among undergraduates at the University of Jordan: are they real or stereotyping? Project Innovation (Alabana), 45(3), 1 -11.

Koocher, G. P. and Keith-Spiegel, P. (2017). Multiple Relationships in Educational Settings. In Zur, O. (Ed.) Multiple Relationships in Psychotherapy and Counselling: Unavoidable, Common and Mandatory Dual Relations in Therapy. New York: Routledge. 
Mamhute, R. (2011). The educational challenges of pregnant and nursing adult learners: A case of Morgenster Teachers' College. D. Ed Dissertation. UNISA.

McKie, R. (2010). The Observe http//observer.guardian.co.uk. Sunday 15 August.

Meiners, E. B. (2017). Role negotiation as role enrichment: A study of working college students. Communication Reports, 1-13.

Rafidah, K., Azizah, A., Norzaidi, M. D., Chong, S. C., Salwani, M. I. and Norraini, I. (2009). The impact of perceived stress and stress factors on academic performance of pre-diploma Science students: A Malaysian study. International Journal of Scientific Research in Education, 2(1), 13-26. Retrieved 30 April 2013 from http://www.ijsre.com.

Reed, M. J. (2016). University massification and teaching non-traditional university students. Invited chapter in J. Arvanitakis \& D. Hornsby D. (Eds.), Universities, the Citizen Scholar, and the Future of Higher Education (pp. 137-154). New York, NY: Palgrave Macmillan.

Reed, M. J. and Kennett, D. J. (2017). The Importance of University Students' Perceived Ability to Balance Multiple Roles: A Comparison of Students with and without Disabilities. Canadian Journal of Higher Education, 47(2), 71-86.

Ritzer, G. (2008). Sociological theory. ( $\left.7^{\text {th }} \mathrm{Ed}\right)$. Boston: McGraw-Hill Higher Education.

Rowlands, S. R. (2010). Non-traditional students: The impact of role strain on their identity. Model Research Paper. Southern Illinois University Carbondale.

Safree, A., Yasin and Dzulkifli, M. A. (2011). Differences in depression, anxiety and stress between lower-high achieving students. Journal of Sustainability Science and Management, 6(1), 169-178.

Silverman, D. (2010). Doing qualitative research. $\left(3^{\text {rd }} \mathrm{Ed}\right)$. London: Sage Publications.

United Nations Zimbabwe. (2010). Country Analysis Report for Zimbabwe. Harare: Government of Zimbabwe.

Van Rhijn, T. M., and Lero, D. (2014). The influence of selfefficacy beliefs for student parents attending university. International Journal of Lifelong Education, 33(4), 541-555.

Veney, C., O'Green, V. and Kowalik, T. F. (2012). Role strain and its impact on non-traditional students' success. Strategic Enrolment Management: American Association of Collegiate Registrars and Admissions Officers.

Vitasari, P., Wahab, M. N. A., Othman, A., Herawan, T. and Sirriadurai, S. K. (2010). The relationship between study anxiety and academic performance among engineering students. Procedia 'Social and Behavioural Sciences, 8, 490-497.

Wadesango, N. and Machingambi, S. (2011). Causes and structural effects of student absenteeism: A case study of three South African Universities. Journal of Social Science, 26(2), 38-46.
Wakefield, K. M. (2013). Making measuring of adversity. Coping and self-authorship in undergraduate students. Dissertation. University of Michigan.

Whipps-Johnson, J. (2016). Teachers' Awareness of Cultural Diversity and Academic Achievement in Ninth Grade Academies and Senior High Schools. Dissertations. 265. https://aquila.usm.edu/dissertations/265

Wilkinson, R. G. and Marmot, M. (2006). Social determinants of health: The solid facts. $\left(2^{\text {nd }} \mathrm{Ed}\right)$. Oxford: University Press.

Willems, J. (2010). The equity raw-score matrix-a multidynamical indicator of potential disadvantages of higher education. Higher Education Reserve and Development. 